\title{
Study on High energy efficiency photovoltaic facility agricultural system in tropical area of China
}

\author{
Zhiwu $\mathrm{Ge}^{1}$, Tiantian $\mathrm{He}^{2}$, XiaoYanyang ${ }^{1}$, JianbiaoDai ${ }^{3}$ XuefeiJiang ${ }^{4}$ \\ ${ }^{1}$ Hainan normal University, Physics Department, No. 99, Long Kun south road, Haikou, China \\ ${ }^{2}$ Hainan normal University, Horticulture Department, No. 99, Long Kun south road, Haikou, China \\ ${ }^{3}$ Shanghai JiaoTong University, Physics Department, No. 800 Dongchuan RD. Minhang District, Shanghai, China \\ ${ }^{4}$ Hainan University, Horticulture Department, No. 58 People's RD, Haikou, China
}

\begin{abstract}
The photovoltaic facility agriculture is developing rapidly in recent years, but there are many problems brought out, even in some important demonstration projects, due to the lack of standards. In order to solve some of these problems, we set up a photovoltaic facilities agricultural system in Guilinyang University City, Haikou, China and make an in-depth study on the photovoltaic facility agricultural system and its related problems. In this paper we disclose some of the experimental results. We plant corianders under two kinds of solar cell panels and general double glass assembly already sold on the market. Experiments showed that the square format cell panels are much better than row type, and the next one is general double glass assembly sold on the market, the last is the case without any shelter. 30 days after planting, the height of coriander plants are $50 \mathrm{~mm}, 30 \mathrm{~mm}, 23 \mathrm{~mm}$ and $20 \mathrm{~mm}$ correspondingly. The two typical solar cell panels have gaps between cells, and can save much more energy and improve power generation efficiency, we arrange the panels at optimum tilted angle, and design the system as open structure to save more energy. The photovoltaic facilities agricultural system we set up in Guilinyang University City can achieve much high solar energy efficiency than others and has broad application prospects.
\end{abstract}

\section{Preface}

With the growing development of people's living standard, the material demand is growing also. The resource consumption will greatly increase. But as the earth's non-renewable resources is becoming less and less, it is possible to exhaust the non-renewable resources in the near feature. In the exploration process of new energy, it is found that the light energy from the sun is almost inexhaustible, and it is the first choice to take the place of the non-renewable resources[1-3].

In recent years, under national policy support, solar energy has become a fast growth energy application form all over the world. China also spare no effort in the development and applications of solar energy[1-3].

These days photovoltaic facility agriculture is developing rapidly, Because of the common and complementary aspect of photovoltaic (PV) and agriculture on the land use, the industry has been seeking a combination for breakthrough, making it one of the important developing direction currently[4-9].

But because the lack of national standards, many problem occurred, even in some important demonstration projects. The main problem need to solve is how to consider both the photovoltaic power generation and plant yield above the same field. In this paper, we will try to solve this problem[4-9].

\section{High-efficiency photovoltaic facilities agricultural system}

In order to study the solar panels effects on plants below, we set up a photovoltaic facilities agricultural system in Guilinyang University City, Haikou, China. Fig.1 shows the photo of this system and Fig.2 shows the typical solar panels of different structure.

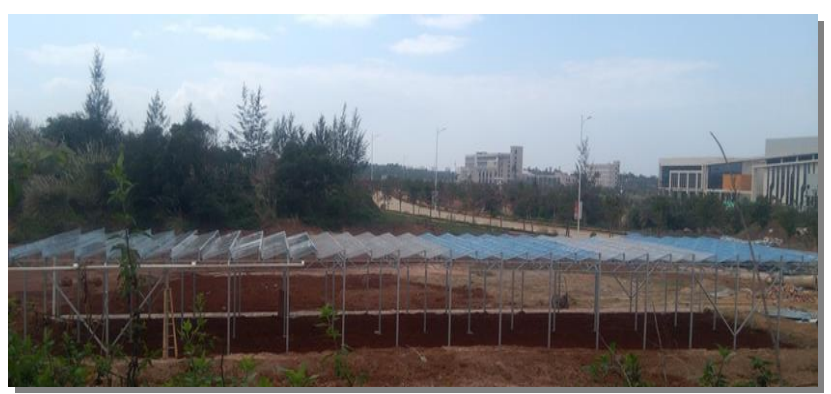

Figure1. Photo of tropical high-efficiency photovoltaic facilities agricultural system in Guilinyang University City, Haikou, China

There are gaps between the photovoltaic cells, and sunlight can cast directly on the ground without absorption. For typical double glass solar components, the theoretical sunlight transmittance $\mu$ is 


$$
\begin{aligned}
\mu & =\mu_{1} \times \mu_{2} \times \mu_{3} \\
& =92 \% \times 91.5 \% \times 92 \% \\
& =77.4 \%
\end{aligned}
$$

$\mu_{1}$ and $\mu_{3}$ is the total solar transmittance of glasses, $\mu_{2}$ is is the solar transmittance of EVA film.

So we can get that the loss of sunlight ratio $\mu_{\mathrm{L}}$ is

$$
\mu_{\mathrm{L}}=1-77.4 \%=22.6 \%
$$

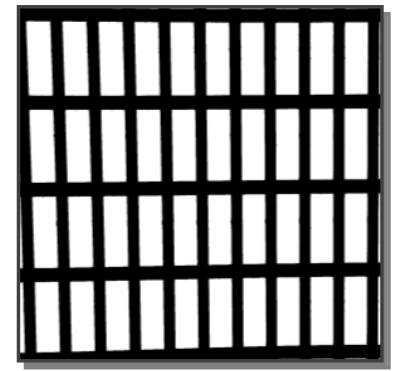

(a)

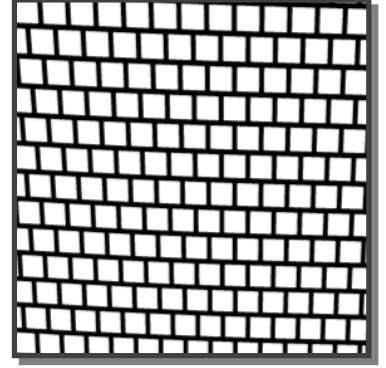

(b)
Figure.2 solar panels of different structure

\section{Study on the effects of corianders planted under different solar panels}

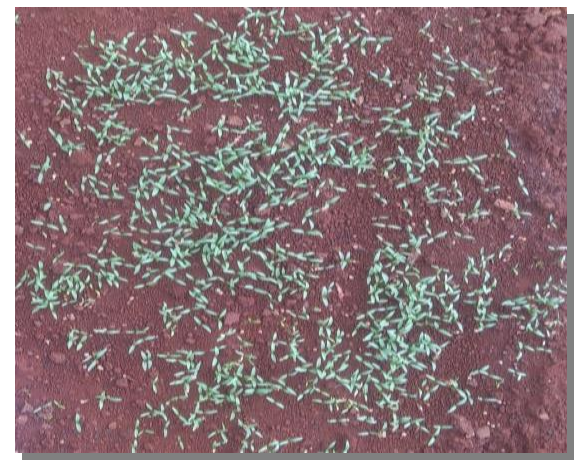

(a)

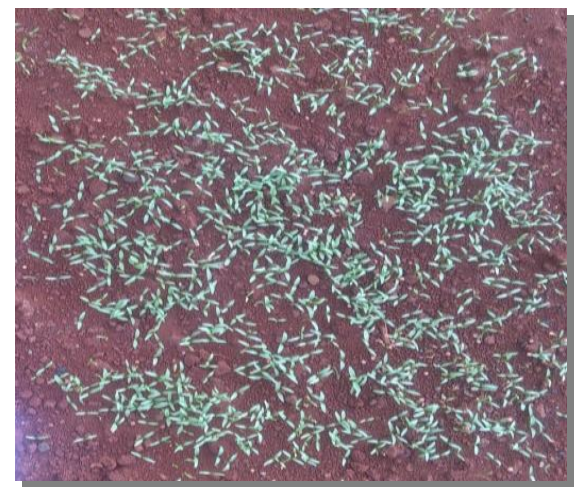

(b)

Figure 3. Photos of coriander taken in March 3rd

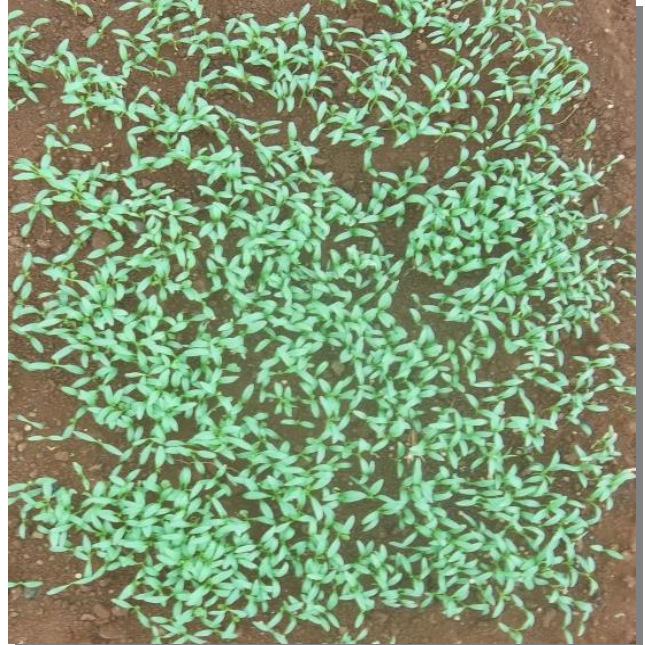

(a)

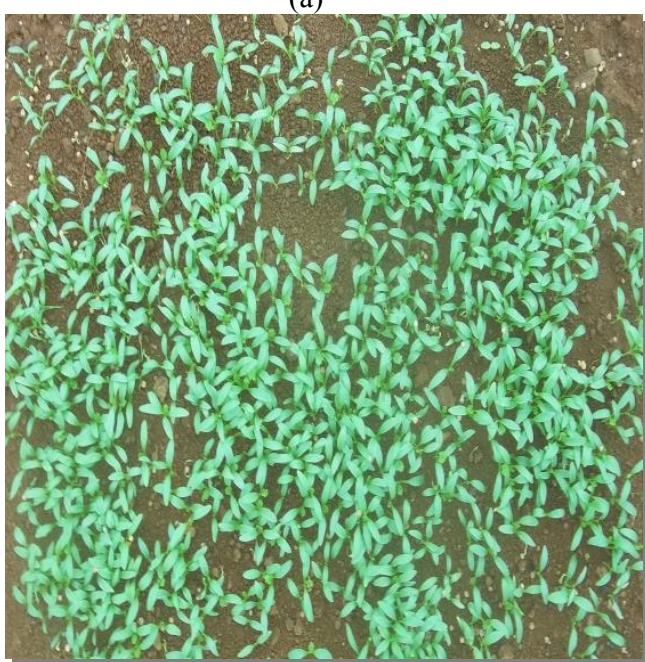

(b)

Figure 4. Photos of coriander taken in March 7th

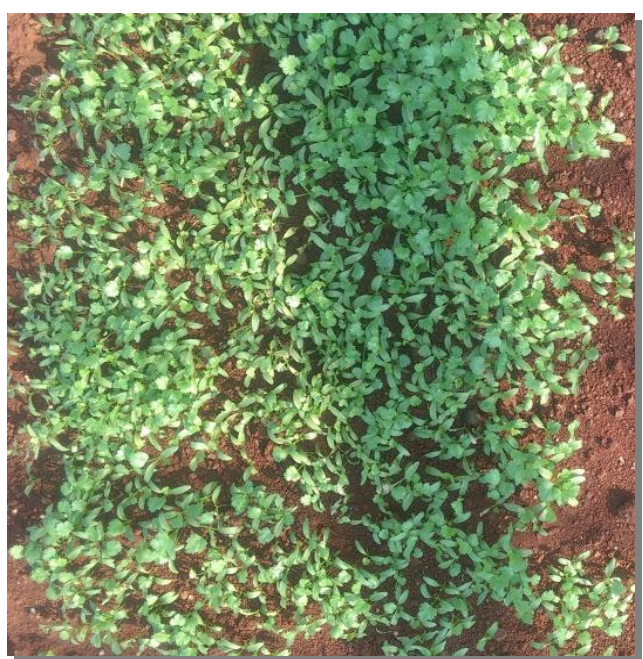

(a) 


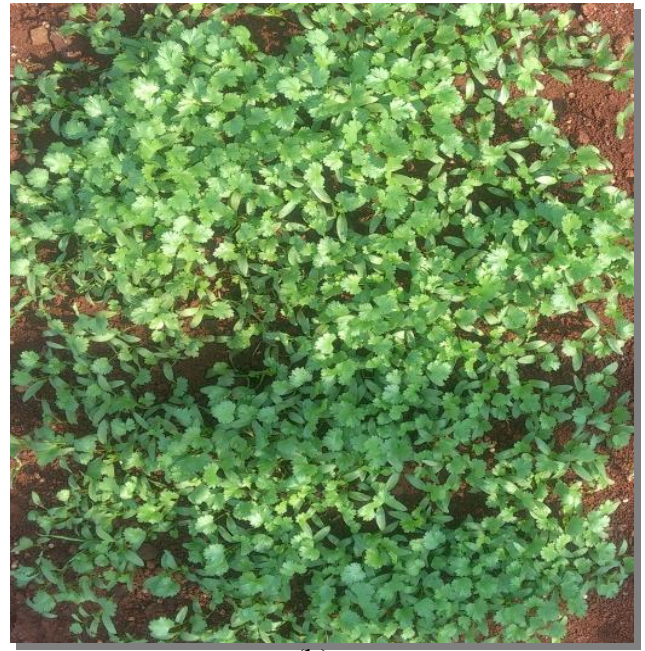

(b)

Figure 5. Photos of coriander taken in March 13th
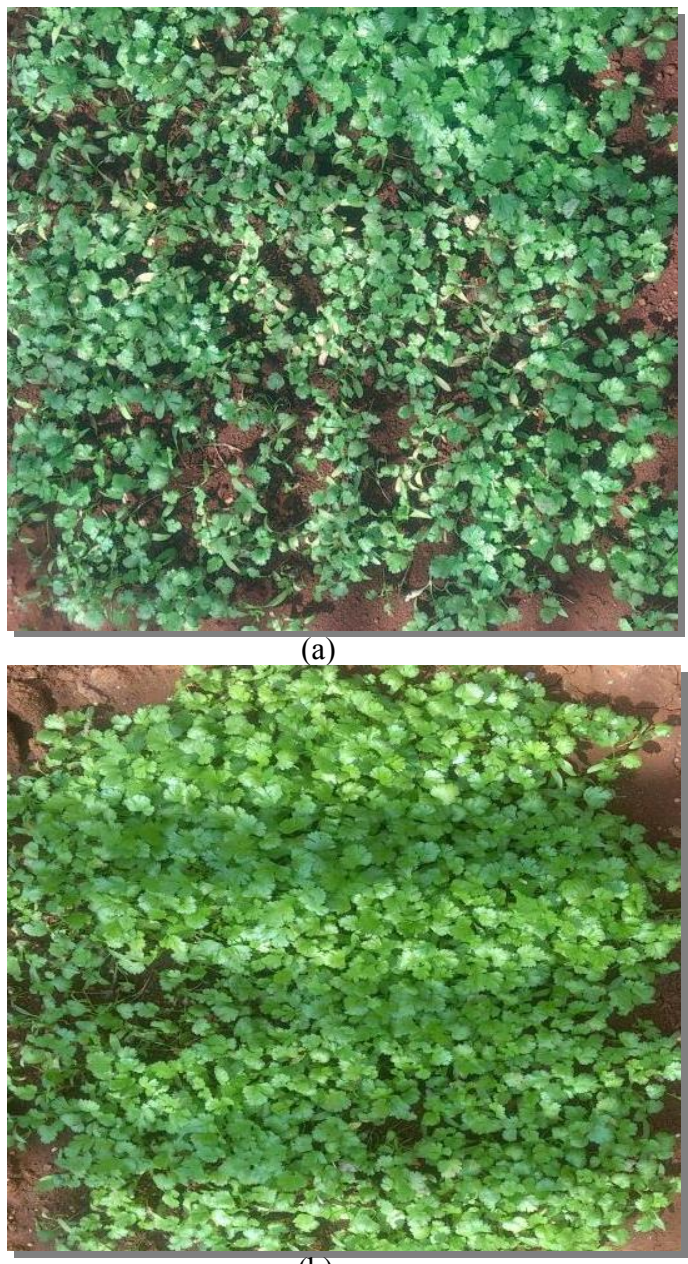

(b)

Figure 6. Photos of coriander taken in March 21st

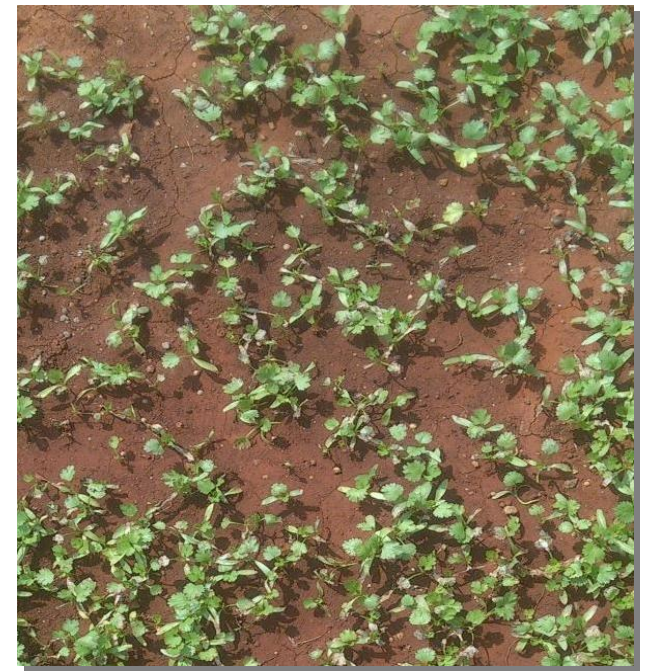

(a)

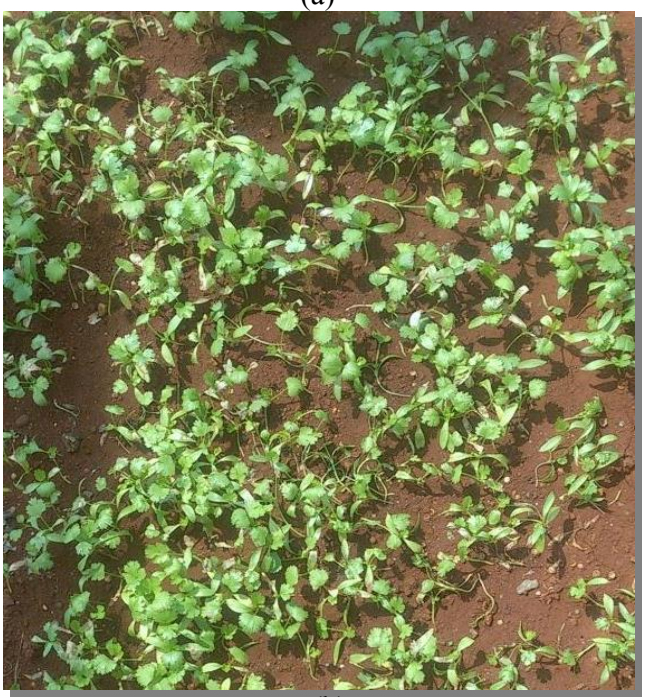

(b)

Figure7. Photos of the other coriander taken in March 21st

The corianders were planted in February 19th, 2017, under different solar panels.

Fig. 3(a) to Fig. 6(a) were photos of corianders planted under solar panels as shown in Fig.2(a), and Fig. 3(b) to Fig. 6(b) were photos of corianders planted under solar panels as shown in Fig.2(b). We water each plant as often as require, and all the other conditions are the same.

From February 19th to March 3rd, 10 days after planting, corianders speared out of the earth one after another. Fig. 3 shows the photos of planted corianders taken in March 3rd, 12 days after planting. Fig.4 shows the photos of coriander taken in March 7th, 16 days after planting. Fig. 5 shows the photos of coriander taken in March 13th, 22 days after planting. Fig. 6 shows the photos of coriander taken in March 21st, 30 days after planting. In each figure, compare the photo(a) to photo(b), It can be seen that over time, the difference becomes more and more obvious. Corianders planted under solar panels as shown inFig.2 (b) growth much better and yield highly compare with that under Fig.2 (a). Fig. 7 shows the photos of the coriander under other conditions taken in March 21st,

Fig. 7(a) shows the photos of coriander plants grow naturally, without any shelter, and Fig. 7 (b) shows the 
photos of coriander plants grow under general double glass assembly sold on the market.

We measured the height of coriander plants at March 21st, 30 days after planting, and got the quantitative results, the average height $\mathrm{H}_{1}$ of plants in Fig.6(b) is $50 \mathrm{~mm}$, while $\mathrm{H}_{2}$ in Fig.6(a) is $30 \mathrm{~mm}, \mathrm{H}_{3}$ in Fig.7(a) is $20 \mathrm{~mm}$, and $\mathrm{H}_{4}$ in Fig.7(b) is $23 \mathrm{~mm}$. Fig.7(a) shows the case without any shelter, so it a can be set as comparative benchmarks for height comparison.

$$
\begin{aligned}
& R_{13}=\frac{H_{1}-H_{3}}{H_{3}}=\frac{50-20}{20}=150 \% \\
& R_{23}=\frac{H_{2}-H_{3}}{H_{3}}=\frac{30-20}{20}=50 \% \\
& R_{43}=\frac{H 4-H_{3}}{H_{3}}=\frac{23-20}{20}=15 \%
\end{aligned}
$$

$\mathrm{R}_{13}, \mathrm{R}_{23}$ and $\mathrm{R}_{43}$ are the height comparison ratio of case shows in Fig.6 and Fig.7(b) compared with that in Fig.7(a).

The reasons of above results are that solar panels in Fig.2(a) and (b) have much higher sunlight transmittance than general double glass assembly sold on the market, and also just proper for plants grows, compared with that in Fig.7(a) and (b), there are too much sunlight in Fig.7(a) and too less in Fig.7(b). The reason of coriander plants shown in Fig.3(b) to Fig.6(b) yield much than Fig.3(a) to Fig.6(a) is that solar panels in Fig.2(b) can cast fairly well-distributed sunshine than that under Fig.2(b) [13-17].

\section{Conclusion}

For typical double glass solar components, the theoretical sunlight transmittance is $77.4 \%$, a lot of solar energy has been lost, this caused because of the absorption of EVA film and glasses, field tests showed that the real solar energy loss is more than $26 \%$. Using the special solar panels whit gaps, the direct solar energy utilization ratio increased by $26 \%$, and by proper arrangement, the crop yield can also increase significantly, in our experiment, the crop height increased by more than $50 \%$, other parameters have been detected and will be analyzed in detail and publish later.

In this photovoltaic facility agricultural system, the wind and plant under solar panels can reduce the temperature of silicon solar cells, resulting in improved power efficiency[10], and all the solar panels were arranged at optimum tilted angle to get the most solar energy[11-12]. The open structure caused the system to maximize the use of local natural climatic conditions, and does not require other electrical energy consumption equipment to adjust.

So our photovoltaic facilities agricultural system set up in Guilinyang University City has much high efficiency than others.

\section{Acknowledgement}

This work was financially supported by the Hainan Natural Science Foundation in 2016(Grant Number 20165198) and 2015 key projects fund of Haikou National University Science and Technology Park.

\section{References}

1. 1.http://xueshu.baidu.com/s?wd=paperuri:(c8a0b8d5 1472 cede $3 \mathrm{~d} 00 \mathrm{a} 617 \mathrm{f} 9 \mathrm{c} 147 \mathrm{c}) \&$ filter=sc long_sign\&s c_ks_para $=\mathrm{q} \% 3 \mathrm{D} \% \mathrm{E} 6 \% \mathrm{~B} 5 \% \mathrm{~B} 7 \% \mathrm{E} 5 \% \mathrm{8D} \% 97 \% \mathrm{E} 7$ \%9C\%81\%Е5\%A4\%AA\%E9\%98\%B3\%Е8\%83\%B D\%E5\%88\%A9\%E7\%94\%A8\%Е7\%8A\%B6\%Е5\% $86 \% \mathrm{~B} 5 \% \mathrm{E} 8 \% \mathrm{~B} 0 \% 83 \% \mathrm{E} 6 \% 9 \mathrm{~F} \% \mathrm{~A} 5 \& \mathrm{tn}=\mathrm{SE}$ baidux ueshu_clgjeupa\&ie $=$ utf8\&sc_us $=732717828369385$ 3975

2. Xufei. zhang. Renpeng. Xiao, Science and Technology and Equipment, 12, 35-37,(2010).

3. Yi .shen, Thesis of Lanzhou University, 1-13,(2014)

4. Zhiwu Ge, Yue Li, Chengling Bian, Study of a typical photovoltaic greenhouse in Hainan tropical island , 2016_5th International Conference on Energy and Environmental Protection, Shenzhen, China. September 17-18, 2016, Accepted

5. Zhiwu Ge, RuipingWang, The survey of photovoltaic agricultural development in Hainan, Science and Technology Economic Herald, 2017, (3): 110-111

6. GeZhiwu, Design of Small scale Independent photovoltaic facilities above farm land, 2014 International Conference on Environmental Protection and Human Health, Wuhan, Hubei, China, December 13-14, 2014,236-239

7. Xu Yong, discussion on some problems of solar greenhouse, modern agricultural science and technology, 2015, (11): 29-32

8. http://solar.ofweek.com/2014-06/ART-26000911000-28835847.html

9. http://guangfu.bjx.com.cn/news/20161201/793211.sh tml

10. YanXialin, Zhiwu Ge, etc., Study on temperature and power generation efficiency of crystalline silicon solar cells, 2017, (11): 42-43

11. XiaoYanyang, Zhiwu Ge, etc., Structure and wind resistance design of photovoltaic facilities agriculture system in Guilin University Town, 2017, (11): 87,68

12. Study on the optimum tilted angle of solar cells in Hainan tropical photovoltaic facility agricultural system, The 2017 3rd International Conference on Energy Materials and Environment Engineering, Bangkok, Thailand, March 10-12, 2017 :012073

13. Gezhiwu*,Bianchengling, Liujie, Research on the effect of photovoltaic solar cells setting up above farmland, 2015 International Conference on New Energy Science and Research, Changsha, Hunan, China, June 20-21, 2015. 52-56.

14. Gezhiwu*,Zhouyu, Analysis of photovoltaic Cell Arrangement in the Independent solar Power generating System Installed above Farm Land, 2015 Information Technology and Mechatronics Engineering Conference, Chongqing, China, March 28-29, 2015 , vol.7, 87-89. 
15. Zhi Wu Ge*,Xue Fei Jiang, Research on the solar cell arrangement and its effect on the photovoltaic protected agriculture systems in the Hainan tropical region, 2015 International Conference on Architectural , Energy and Information Engineering, Hong Kang, China, July 15-16,2015, 253-256

16. Gezhiwu*, Bianxiufen, Weijiande, Design of Small scale Independent photovoltaic facilities above farm land , 2014 International Conference on Environmental Protection and Human Health,
Wuhan, Hubei, China, December 13-14, 2014,236239

17. Gezhiwu*, XiaoRixin, WangRuiping, Influence of solar Panels in distributed photovoltaic Power generating System above Farm Land on Field and Crops,The2014 International Forum on Applied Energy and Environment, Shenzhen, Guangdong, China, November 28-29, 2014. Applied Mechanics and Materials Vol.737,20-23 